\title{
A Successful Model for Partnership between Community College and Univer- sity Engineering Departments Leading to Expanded Access to Baccalaureate Engineering Education
}

\section{Mr. Eric James Davishahl, Everett Community College}

Eric Davishahl has been faculty and department chair in the Engineering and Computer Science Department at Everett Community College since Fall 2001. During that time he has overseen a rapid expansion evidenced by enrollment growth from 20 to over 150 full time equivalent students and associated staffing growth from one to eight full-time equivalent faculty. Eric has collaborated on several statewide articulation initiatives in Washington and was the recipient of the ASEE Pacific Northwest Section Outstanding Teaching Award in 2008. Eric has taught nearly every freshman and sophomore level engineering course multiple times.

\section{Dr. Xiaopeng Bi, Washington State University}

Xiaopeng Bi, Program Coordinator for the WSU Everett Mechanical Engineering program, was one of the two founding faculty members for the program in 2012. He has taught twenty-five engineering courses over the past eight years. He has been actively coaching various student design and competition projects such as Electrathon America, University Rover Challenge, and Unmanned Aerial Vehicles. Dr. Bi received his Ph.D. in Aerospace Engineering from the University of Illinois at Urbana-Champaign in 2003. His research interests include engineering education, aircraft and vehicle related engineering design, and dynamic failure and fracture of structures and materials. 


\title{
A Successful Model for Partnership between Community College and University Engineering Departments Leading to Expanded Access to Baccalaureate Engineering Education
}

\begin{abstract}
Increasing numbers of engineering students are starting their higher education at a community college with intent to transfer to a four year university to complete their Bachelor of Science degree. To facilitate the transition from community college to junior year university studies, new partnership models have been developed that offer more flexibility to students without sacrificing higher education quality. This paper shares details of a successful partnership between Everett Community College (EvCC) and Washington State University (WSU) to offer the WSU Mechanical Engineering (BSME) degree on the EvCC campus in Everett, WA. Extending the WSU BSME program to a location on the EvCC campus has proven to be very helpful and attractive to students from a variety of backgrounds and life situations that are historically underrepresented in the engineering undergraduate population. Enrollments in both programs have been growing steadily since the inception of the BSME program in fall 2012. Following the success of the BSME program, WSU used a similar model to add an electrical engineering (BSEE) program on the EvCC campus in fall 2014 and plans to start a software engineering (BSSE) program in fall 2016. Close collaborations have been built to leverage the knowledge, skills, and facilities of both institutions to provide a rich student experience with often limited resources. Community college students can enroll in some of the same classes as junior level WSU students before making the transfer, thus gaining exposure to the upper division experience before committing to the WSU program and providing opportunities for social mixing of sophomore and junior level students not typically available to community college sophomores. Collaborative relationships among faculty and students at the two institutions ensure the transition to be as seamless as possible. This paper provides an overview of the governing articulation agreements under which the program operates before sharing details regarding how the two programs align and integrate specific course curriculum, manage logistics such as course scheduling and equipment sharing, and provide overall continuity in the student experience. We also share some initial enrollment demographics data that indicates the program is helping the WSU BSME program extend its reach to serve historically underrepresented student populations.
\end{abstract}

\section{Introduction}

Increasing numbers of engineering students are starting their higher education at a community college with intent to transfer to a four year university to complete their Bachelor of Science 
degree. ${ }^{1}$ Community colleges play a substantial role in the production of engineering graduates in Washington State. Several community colleges throughout the state offer comprehensive engineering transfer programs that include all the courses necessary for students to transfer at junior level in most engineering majors. Transfer students who completed their prerequisite course work at a community college make up approximately one third and one quarter of engineering graduates at the main campuses of Washington State University in Pullman and University of Washington in Seattle respectively. More broadly 36\% of 2014 college graduates in Washington had completed at least some community college credits within the previous ten years. $^{2}$

As demand for engineering graduates in Washington has grown over the past decade, there have been efforts on several fronts to increase engineering baccalaureate capacity in the state's public higher education system. The following capacity increases have been funded by appropriations approved by the state legislature.

- Both University of Washington (UW) and Washington State University (WSU) have added capacity in several engineering majors on their main campuses.

- New engineering programs have been added at branch campuses for both universities. UW Bothell now offers degrees in electrical, mechanical, and computer engineering. Washington State University offers degrees in mechanical and electrical engineering at WSU Vancouver as well as degrees in mechanical, civil, and electrical engineering at WSU Tri-Cities.

- New programs have been launched at the regional universities. Eastern Washington University has added majors in mechanical, electrical, and computer engineering to their engineering technology program offerings. Western Washington University recently converted their main engineering technology programs to engineering.

- Satellite programs have been created where a university partners with a community college to offer a Bachelor of Science degree in engineering on the community college's campus. As of Fall 2015, there are three such programs in Washington. Eastern Washington University offers a Bachelor of Science in electrical engineering on the campus of North Seattle College. Washington State University offers Bachelor of Science degrees in mechanical and electrical engineering at both Olympic College and Everett Community College (EvCC).

Each of these satellite programs involve unique challenges and opportunities associated with local industry, the culture of the community college, and student demographics. This paper focuses on WSU's engineering program offerings on the EvCC campus. We will describe in detail the history of the collaboration between EvCC and WSU's Voiland College of Engineering and Architecture that make this program possible and successful. Programs involving co-enrollment partnerships between two-year and four-year institutions have shown promise toward smoothing the transfer process and improving retention, particularly for students 
from historically underrepresented populations. ${ }^{3}$ We will discuss the strengths and challenges of this program model in hopes other colleges can learn from our experience. Lastly we will present some early data that indicates the program is reaching historically underserved populations in greater numbers than the main campus.

Before moving forward, some information about these two partnering institutions might be helpful to those considering in whether a similar model could work at their college. Everett Community College is a comprehensive community college located in Everett, Washington, which is 29 miles north of Seattle. EvCC has a total enrollment of about 19,000 students (including full and part time students) and offers an array of certificate and degree programs including academic transfer, professional/technical, and adult basic education. At the time this partnership started in fall 2012, EvCC already offered a comprehensive engineering transfer curriculum with one or more annual offerings of each of the prerequisite courses in math, science and engineering necessary for students to transfer at junior level to most engineering BS degree programs in the state of Washington. In fall 2012, the engineering transfer program had a total enrollment of about 200 full and part-time students with about 40 students per year transferring at or near junior level to engineering programs at colleges and universities in Washington state and elsewhere.

Washington State University is a land grant university with its main campus located in Pullman, Washington near the Washington -Idaho border, approximately 300 miles southeast of Everett. Currently WSU serves more than 20,000 students in Pullman main campus, and more than 9,600 students in Spokane, Tri-cities, Vancouver, Everett and Global Campus. WSU is comprised of 11 colleges, including the Voiland College of Engineering and Architecture (VCEA). As of 2015, the total enrollment in VCEA degree programs includes nearly 4000 undergraduates and more than 650 graduate students ${ }^{4}$. These totals include enrollments in the branch campuses in Tri-Cities and Vancouver, the online Global Campus, and the programs in Everett and Bremerton mentioned above. Annual research expenditures in the WSU VCEA exceeded \$25 million in fiscal year 2014. ${ }^{4}$ The Mechanical Engineering department at WSU is part of the School of Mechanical and Materials Engineering. In 2015, the department had 936 students, including 61 in the Everett BSME program, and 205 graduate students.

\section{Program Inception in Fall 2012}

The collaboration between WSU and EvCC began in early 2012 with planning for a BSME program that would start in fall 2012. At the time, EvCC ran a University Center on campus that offered baccalaureate programs in a variety of majors in partnership with numerous public and private colleges and universities. The new WSU BSME program would fit into this infrastructure and would have an initial capacity of 30 students. Like other Everett University Center programs, the new BSME program would be marketed as a good option for "placebound" students who prefer not to move away from the Everett area to transfer and complete work on a BS degree. Note that prior to the inception of this program, the closest transfer option 
for BSME was at UW-Seattle, located approximately thirty miles to the south of EvCC. The UW-Seattle BSME program is very competitive to gain admission to with average prerequisite GPA in excess of 3.6 in recent years. The new WSU program would operate as a satellite of the BSME program on the main campus in Pullman and would fall under the ABET accreditation of that program as an extension. WSU hired two full time clinical professors for the Everett program. These professors would teach the majority of the courses in Everett, with additional courses being taught by local adjunct faculty or via teleconference with Pullman classrooms.

Two key challenges needed to be overcome in order to launch the program. The first challenge to resolve was to address areas in which the EvCC and WSU curriculums did not align well in order to provide a seamless transition between the sophomore and junior year. This challenge was compounded by the fact that the new WSU program would be accepting transfer students from other nearby community colleges that would not necessarily be making any curriculum changes to better align with the new WSU transfer option. The typical sophomore and junior years of the WSU BSME curriculum are shown below in Table 1 in terms of WSU course numbers.

\begin{tabular}{|c|c|}
\hline \multicolumn{2}{|c|}{ Sophomore Year } \\
\hline Fall Semester & Spring Semester \\
\hline MATH 220: Linear Algebra & MATH 315: Differential Equations \\
\hline MATH 273: Calculus III (Multi-variable) & ME 212: Dynamics \\
\hline PHYS 201: Engineering Physics 1 & PHYS 202: Engineering Physics 2 \\
\hline CE 211: Statics & CE 215: Mechanics of Materials \\
\hline EE 221: Comp Prog w/MATLAB & ME 220: Materials Lab \\
\hline ECON 102: Macroeconomics & ME 216: Integrated CAD \\
\hline \multicolumn{2}{|c|}{ Junior Year } \\
\hline Fall Semester & Spring Semester \\
\hline ME 301: Thermodynamics & ME 306: Thermofluids Lab \\
\hline ME 201: Materials Science & ME 310: Manufacturing Processes \\
\hline MATH 370: Statistics & ME 311: Manufacturing Processes Lab \\
\hline ME 303: Fluid Mechanics & ME 316: Engineering Design \\
\hline ME 313: Engineering Analysis & ME 348: Dynamics Systems \\
\hline EE 304: Circuits & ME 304: Heat Transfer \\
\hline
\end{tabular}

Table 1: WSU BSME program sophomore and junior year curriculum. 
As of early 2012, when program details were being determined, EvCC offered transfer equivalents of all of the sophomore year courses with the exception of ME 220 and ME 216. The University Center agreements under which this program was to operate encouraged the sharing of teaching resources, so it was a natural solution for the EvCC engineering program to develop versions of these two sophomore level courses. One challenge here was in funding the equipment needed for the Materials Lab. EvCC already owned a suitable 50-kN materials testing machine that was the most expensive piece of equipment for this lab. WSU agreed to purchase the remainder of the required equipment to furnish an EvCC lab classroom with all the equipment necessary to offer an equivalent to ME 220.

A second challenge with ME 220 and ME 216 was that no other nearby community college offered them either. The program would need to be designed to accommodate the fact that entering juniors would likely not have these two courses complete, especially if they were transferring from a college other than EvCC. This issue was addressed with modifications, described below, that WSU made to the junior and senior year curriculums in the Everett program. These transfer students would still take the ME 216 and ME 220 equivalent courses from EvCC, but they would do so during their junior year while also taking classes from WSU. This dual enrollment situation was further necessitated by the fact that EvCC already offered equivalents to ME 301: Thermodynamics and EE 304: Circuits that are in the WSU BSME junior year curriculum as shown in Table 1. Since these two courses were already offered by EvCC, it would have been redundant for WSU to offer its own sections of the same courses on the EvCC campus..

Table 2 on the next page shows the modified WSU BSME junior year curriculum for the Everett program at program inception in Fall 2012 along with a typical final year curriculum for a community college engineering transfer student. Note that the local community colleges including EvCC operate on 10-week quarters, in contrast to WSU which operates on 15-week semesters.

The four courses in the WSU junior year with the ENGR prefix (namely ENGR 204, 216, 220 and 224) are offered by EvCC in 10-week quarters. WSU juniors are co-enrolled in both EvCC and WSU for their junior year unless they have completed all four of these ENGR courses. This arrangement presents a bit of a challenge for students reconciling the EvCC quarter system calendar with the WSU semester calendar with different start and stop dates. A further challenge comes as a result of the different pace and intensity of a 10-week course versus a 15week course. Fall semester is particularly challenging for students as EvCC's thermodynamics course starts after students have completed five weeks of their WSU fluid mechanics course, this despite a concurrent enrollment requirement for the two courses. Students have, for the most part, been able to handle this calendar and pace discrepancy with few issues. The dual enrollment of the junior year, while it arose out of a series of solutions to logistical issues as described above, has proven on balance to be beneficial to students and we see this approach as one of the strengths of the program model as will be described in more detail later in this paper. 


\begin{tabular}{|l|l|l|}
\hline \multicolumn{3}{|c|}{ "Sophomore" Year (typical Community College student finishing up) } \\
\hline Fall Quarter & Winter Quarter & Spring Quarter \\
\hline MATH 264: Calc 4 & MATH 260: Linear Algebra & MATH 261: Diff EQ \\
\hline PHYS 242/232: Phys 2 & PHYS 243/233: Phys 3 & ENGR 225: Mech of Mat \\
\hline ENGR 214: Statics & ENGR 215: Dynamics & ENGR 240: MATLAB \\
\hline \multicolumn{2}{|c|}{ Junior Year (WSU BSME Program in Everett) } \\
\hline \multicolumn{2}{|c|}{ Fall Semester } & Spring Semester \\
\hline ENGR 224: Thermodynamics (EvCC) & ENGR 204: Electric Circuits \\
\hline ME 201: Materials Science & ENGR 216: Integrated CAD \\
\hline MATH 370: Statistics & ENGR 220: Mechanics Breaking Lab \\
\hline ME 303: Fluid Mechanics & ME 310: Manufacturing Processes \\
\hline ME 313: Engineering Analysis & ME 348: Dynamics Systems \\
\hline
\end{tabular}

Table 2: WSU BSME program sophomore and junior year curriculum as offered in Everett for the initial student cohort who started fall 2012.

Note three courses from Table 1, ME 306, 311, and 316, that are absent from the junior year curriculum presented in Table 2. ME 316 was moved to the senior year to accommodate transfer students not completing ENGR 216 (the prerequisite course) until the spring semester of their junior year. ME 306 and 311 are both lab courses that were initially moved to a summer term between junior and senior year as part of the initial laboratory solution described in the following paragraph.

The second major challenge in implementing this satellite program was how to provide a comparable laboratory experience to the offerings on the Pullman campus. A mechanical engineering program requires extensive and expensive laboratory space and equipment to provide a quality education experience and meet ABET standards. The WSU BSME curriculum includes five mechanical engineering lab courses:

- ME 220: Materials Lab

- ME 306: Thermofluids Lab

- ME 311: Manufacturing Processes Lab

- ME 401: Mechatronics

- ME 406: Experimental Design Lab

As described above, the decision was made for EvCC to teach an equivalent to the Materials Lab. The initial plan for the remaining lab courses was as follows. It was determined that the 
lab needs of ME 401 could be adequately met by using table top equipment in a traditional classroom. This left ME 306, 311, and 406. Students would complete these three courses in a compressed summer session on the main campus in Pullman (a five hour drive from Everett) in the summer between junior and senior year. While this plan offered the benefit of providing the satellite program students with exposure to the Pullman facilities and equipment, it flew in direct opposition of the stated goal of the program to serve place-bound students. These students were highly unlikely to be able to leave Everett for four weeks in the summer due to job and/or family commitments. Nonetheless, the timeline for program launch (final approval and funding in January 2012 with first cohort starting August 2012) made it impossible to avoid the travel requirement for the first cohort of students.

\section{Program Evolution 2012-2015}

The following developments resulted in incremental changes to the collaboration between the two colleges in the first four years of the program.

WSU secured funding from the state to purchase the equipment necessary to offer the ME 306 and 406 lab courses in Everett, but lacked a suitable space on campus. An agreement was negotiated for WSU to install this equipment in a classroom that EvCC remodeled into a suitable lab space. This work and equipment installation was completed by spring 2014, in time for the Fall 2013 cohort to complete these lab courses in Everett.

EvCC opened the Advanced Manufacturing Training and Education Center (AMTEC) in Fall 2014. This 37,000 square foot industrial facility houses training and certificate programs in precision machining, welding and fabrication, and composites technology. WSU faculty recognized the facility would also provide students with an excellent manufacturing processes lab experience and asked EvCC to develop a course to meet their needs. EvCC machining faculty began offering MFG T 103: Machining for Engineers to meet WSU's ME 311 course requirement starting January 2015, in time for the Fall 2013 cohort to complete the last of their lab courses on the Everett campus during their senior year.

EvCC started offering ENGR 201: Fundamentals of Materials Science in Fall 2014 primarily out of a desire to adequately prepare students for new engineering programs at Western Washington University. There was also recognition that this course offering would increase the options for WSU-bound EvCC students to complete more junior level coursework before transfer, as was becoming popular with many students for reasons described later in this paper. It was subsequently agreed that WSU's first semester juniors would instead take the course from EvCC.

WSU hired a third full time faculty member for the Everett program starting Fall 2015. This addition made it possible for all core courses to be taught in Everett by full time faculty, with only technical electives left to be offered by adjunct faculty and/or interactive video from Pullman. 
With these developments the basic curriculum for the dual enrollment junior year evolved to that shown below in Table 3. Note that students have the option to break the four spring semester EvCC courses (Circuits, Integrated CAD, Breaking Lab, and Machining) over two EvCC quarters (winter and spring) that run roughly parallel to WSU's 15 week semester in order to reduce the intensity of the course load.

\begin{tabular}{|l|l|}
\hline \multicolumn{2}{|c|}{ Junior Year (Dual enrollment in WSU and Everett CC) } \\
\hline Fall Semester & Spring Semester \\
\hline ENGR 224: Thermodynamics & ENGR 204: Circuits \\
\hline ENGR 201: Materials Science & ENGR 216: Integrated CAD \\
\hline MATH 370: Statistics & ENGR 220: Mechanics Breaking Lab \\
\hline ME 303: Fluid Mechanics & MFG T 103: Machining for Engineers \\
\hline ME 313: Engineering Analysis & ME 310: Manufacturing Processes \\
\hline & ME 348: Dynamic Systems \\
\hline & ME 304: Heat Transfer \\
\hline
\end{tabular}

Table 3: WSU BSME program in Everett junior year curriculum for the student cohort who started fall 2015.

The evolution of the junior year curriculum to a point where roughly forty percent of the credits are courses taught by EvCC has provided several unexpected benefits to students.

- The net tuition bill for students when they are dually enrolled part time at both institutions is actually lower than WSU tuition for a full time student. Students can use a consortium agreement to maintain full time status for financial aid purposes, so this situation helps lower the overall cost to students for this BSME degree. This reduced junior year tuition benefit comes on top of other cost savings realized by place-bound students who are now able to continue their education without relocation.

- EvCC transfer students are now able to start taking junior year classes if they have space in their final community college year while they are still finishing up other sophomorelevel prerequisite coursework. In doing so they are able to mix socially with the juniorlevel WSU students and gain some understanding of what lies ahead. This mixing of sophomores and juniors in engineering fundamentals courses is common on university campuses, but it is a rare opportunity at a community college.

- The ability for EvCC sophomores to "test the waters" in one or more WSU junior year courses helps students to clarify their transfer goals. This opportunity also provides for more continuity of experience compared to the typical adjustment period transfer students face when starting at a new institution. 
- Recall that this program targets place-bound students. These students commonly have jobs and/or family commitments that make a conventional full-time engineering course load unrealistic. The dual enrollment model makes it possible for these students to complete a five or even six year degree plan with part time enrollment in most terms. They can do this by completing all of the EvCC portion of the junior year courses before matriculating with WSU. Being a cohort program with a capacity of thirty students, WSU would not be able to offer part time enrollment options to students if it meant halffull WSU courses.

- Students who do complete some of the junior year curriculum become more competitive in their search for internships for the summer between EvCC and WSU.

- The dual enrollment model gives students exposure to a larger number of faculty and more diverse teaching approaches then one would typically expect in a small cohort program like this. In general, a WSU junior will take courses from at least six different full time faculty members on the EvCC campus (three from WSU plus three or more from EvCC).

The EvCC engineering program has a head count of approximately 450 students. Approximately half of these students list mechanical engineering as their intended major. And approximately half of those list WSU's BSME program in Everett as their first choice transfer destination. The benefits described above come mostly to these students, but there are also ways in which this collaboration benefits the entire EvCC engineering student population, including those who do not intend to transfer to any WSU campus and/or do not intend to major in mechanical engineering. Courses such as thermodynamics, electric circuits, and materials science are required prerequisites for junior-level transfer to a number of other engineering majors, but prior to WSU's presence on the Everett campus, insufficient demand meant EvCC did not offer materials science, offered electric circuits once per year, and only offered thermodynamics once every two years. EvCC now offers multiple sections per year of each of these courses, primarily as a result of the dual enrollment model for WSU's juniors. Additionally, any EvCC student can enroll in the Machining for Engineers course that was developed by AMTEC faculty to satisfy WSU's manufacturing processes lab requirement. Freshman and sophomore level students can bring these machining skills to their efforts on student club design projects.

Many of EvCC's entering freshman are first generation college students with little or no exposure to a traditional university experience. The presence of junior and senior level engineering students in the same building, and the informal interactions that frequently occur, help give the newest students a sense for the opportunities that await them if they persist in their education. Some examples of student exposure to these upper-division experiences come with highly-visible efforts of WSU juniors and seniors working on design projects and the annual design project showcase that WSU invites EvCC students to attend:

- A group of WSU BSME students won 2nd place in the 2015 ASEE National Design and Manufacturing Competition. 
- The project "Carnival Time" by two ME students was a finalists and won $2^{\text {nd }}$ place in the 2015 Young Minds Award competition with top honors based on the criteria: creativity, comprehensiveness, clarity of expression, and demonstration.

- WSU Everett Engineering Club was founded in spring 2013. Club students designed, manufactured and programed a Mars rover. The WSU BSME Mars Rover Team has been selected as one of the 30 teams from 7 countries (out of a pool of 63 universities from 12 countries) to advance to the international University Rover Challenge being held June 24, 2016 in Utah.

- As of 2016, all of the WSU BSME programs senior capstone design projects are $100 \%$ sponsored by industry partners such as Boeing.

- A WSU Everett chapter of Society of Women Engineers was founded in 2015 to promote, provide, and enhance the educational and professional opportunities for female students.

\section{Enrollment Trends}

Initial student recruitment for the BSME program's fall 2012 cohort started in January 2012 with a significant headwind. By this time, most students who were on track to complete their prerequisite coursework for a fall 2012 transfer already had their minds set on other options. A further challenge was the travel requirement for the summer laboratory courses in Pullman. Nonetheless, the initial program enrollment was 24 students. The program has been full to capacity in each year since. As competition for the thirty spots has increased, the average transfer GPA for admitted students has increased as well. Figure 1 illustrates this trend.

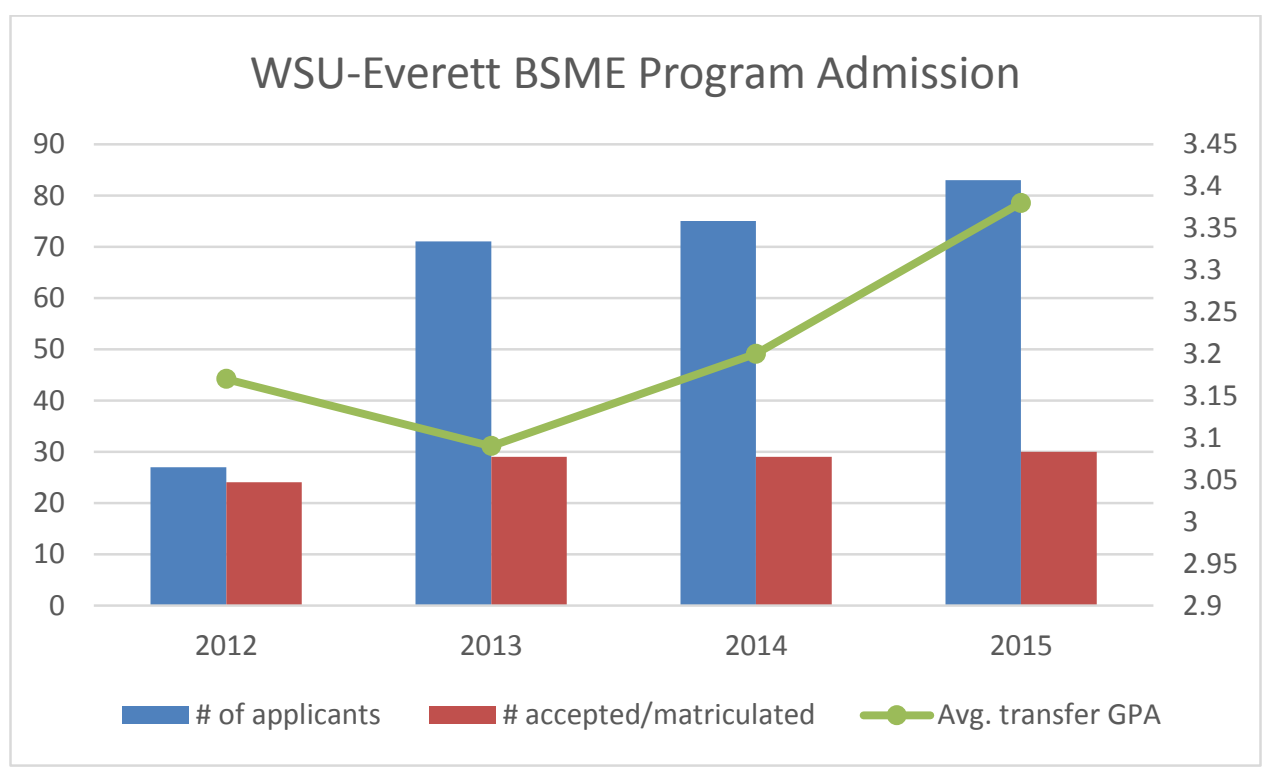

Figure 1: Admission statistics for WSU BSME program in Everett since program inception in Fall 2012. 
Everett Community College's engineering program has also seen substantial enrollment growth of over 100\% since fall 2011 as shown below in Figure 2. WSU's presence on campus has contributed to this growth in three ways. One contributor directly attributable to WSU is the enrollment of WSU juniors in the 200-level courses that are part of the dual-enrollment junior year. A second, less direct contribution to EvCC's rapid growth has been the way in which WSU's presence in Everett has increased the visibility of the EvCC engineering transfer program. The third WSU-related contribution to EvCC's growth is the shift in student enrollment behavior with increasing numbers of students staying at $\mathrm{EvCC}$ for a third year to complete all possible engineering prerequisite courses before transfer.

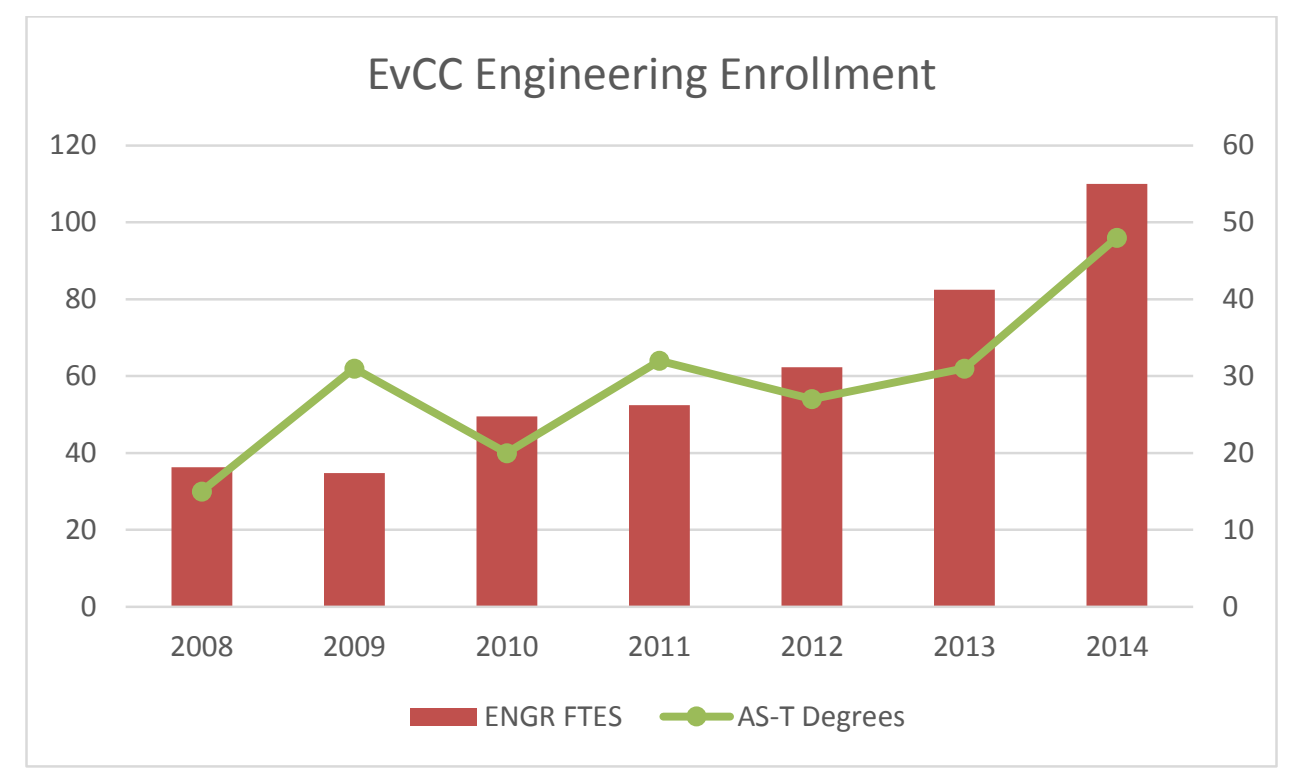

Figure 2: EvCC engineering program enrollment measured by full-time equivalent student enrollment in ENGR prefix course and Associate of Science degree completion.

\section{Student Demographics}

To date, the student demographics in the satellite BSME program have indicated some increased enrollment and retention of underrepresented students compared to the student demographics on the main campus in Pullman. Table 4 on the next page compares demographics of the spring 2016 enrollment in the Everett BSME program compared to the BSME program on the main campus in Pullman.

As evidenced by the data in the table, the Everett program has been more successful at attracting and retaining women with $16.4 \%$ female enrollment compared to $8.5 \%$ enrollment in Pullman. Minority enrollment in the Everett program is also higher than in Pullman with a total minority enrollment of $31.1 \%$ (excluding international students) in Everett compared to $26.1 \%$ in Pullman. Further evidence that the Everett program is expanding the reach of WSU to new populations comes in the average student age for Everett students of 24.5 years, a few years older than the average age in Pullman, where enrollment is dominated by students of traditional 
college age. These enrollment demographic trends are not necessarily a result of outreach and recruitment efforts targeted at women and minorities. They are most likely due to the fact that

\begin{tabular}{|l|c|c|c|c|}
\hline \multirow{2}{*}{$\begin{array}{c}\text { Spring 2016 } \\
\text { WSU BSME Enrollment }\end{array}$} & \multicolumn{2}{c|}{ Everett Program } & \multicolumn{2}{c|}{$\begin{array}{c}\text { WSU Pullman } \\
\text { (Main Campus) }\end{array}$} \\
\hline & Head Count & Percent & Head Count & Percent \\
\hline Male & 51 & $83.6 \%$ & 646 & $91.5 \%$ \\
\hline Female & 10 & $16.4 \%$ & 60 & $8.5 \%$ \\
\hline Total & 61 & $100 \%$ & 706 & $100 \%$ \\
\hline$-\quad$ Asian American & 10 & $16.4 \%$ & 43 & $6.1 \%$ \\
\hline- Hispanic & 3 & $4.9 \%$ & 70 & $9.9 \%$ \\
\hline- American Indian & 0 & $0 \%$ & 1 & $0.1 \%$ \\
\hline- Black & 2 & $3.3 \%$ & 20 & $2.8 \%$ \\
\hline- Pacific Islander & 1 & $1.6 \%$ & 1 & $0.1 \%$ \\
\hline$-\quad$ White & 39 & $63.9 \%$ & 416 & $58.9 \%$ \\
\hline$-\quad$ Two or More & 1 & $1.6 \%$ & 49 & $6.9 \%$ \\
\hline$-\quad$ International & 2 & $3.3 \%$ & 94 & $13.3 \%$ \\
\hline$-\quad$ Unknown & 3 & $4.9 \%$ & 12 & $1.7 \%$ \\
\hline
\end{tabular}

Table 4: Demographics of WSU BSME Everett program enrollment compared to all WSU BSME enrollment at the main campus in Pullman. Data is from Spring semester 2016.

nearly every student in the Everett program, with the exception of a few transfers from Pullman, started their college education at a community college in western Washington and that community college enrollment tends to be more diverse.

\section{Conclusion}

The collaboration between WSU and EvCC to offer a BSME degree in Everett has proven successful at increasing access to engineering baccalaureate education in Snohomish County with a cost-efficient approach that leverages existing program space and faculty expertise at Everett Community College. The educational experience and opportunities available to all EvCC engineering students is enhanced by the presence of WSU on campus both by the increased availability of courses useful for transfer preparation in a variety of engineering majors at other universities, and by a smoother transition into junior level studies for students who choose to stay in Everett with WSU. The dual-enrollment model for the junior year curriculum offers community college sophomores social and academic interaction with junior-level students and access to junior level courses. WSU juniors benefit from the dual enrollment model through exposure to a more diverse set of faculty and reduced tuition. Program enrollment data from 2015-16 indicates the Everett program has been successful at increasing the WSU mechanical engineering program's reach to historically underrepresented populations, particularly women.

Looking forward, WSU is increasing its presence and visibility in Everett. WSU recently broke ground on a new building that is located adjacent to the EvCC campus with completion anticipated by fall 2017. The BSME program will occupy most of the first floor of the building 
with new state-of-the-art facilities and will be increasing capacity from 30 to 40 students for Fall 2016.

${ }^{1}$ Olson, S., Labov, J.B., \& National Research Council. (2012) Community Colleges in the Evolving STEM Education Landscape: Summary of a Summit. Washington D.C.: National Academies Press.

${ }^{2}$ National Student Clearinghouse Research Center. Snapshot Report 17. "Contribution of Two-year Institutions to Four-year Completions" (2014).

${ }^{3}$ Cortez, M. M., Reed, T., Imbrie, P.K., Perez, J. (2015) Expanding the Education Pathway to Undergraduate Engineering Through Strategic Two-year and Four-year Institution Partnerships. Proceedings of the 122 $2^{\text {nd }}$ Annual ASEE Conference and Exposition, Seattle, WA.

${ }^{4}$ Voiland College of Engineering and Architecture Strategic Plan 2015-2020. https://vcea.wsu.edu/facultystaff/documents/2015/05/vcea-strategic-plan-2015-2020-final.pdf 